\title{
Mevcut Bir Yapının Güçlendirme Performansının Değerlendirilmesi
}

\author{
${ }^{1}$ Selçuk SOYDAN ve ${ }^{* 2}$ Necati MERT \\ ${ }^{1}$,SAÜ. Fen Bilimleri Enstitüsü; Esentepe Kampüsü, Sakarya, TÜRKIYYE \\ *22Mühendislik Fakültesi İnşaat Müh. Bölümü, Sakarya Üniversitesi, TÜRKIYE
}

\begin{abstract}
Following the Marmara Earthquake of 17 August 1999, many structures identified as Medium Damaged continue to be used. While the strengthening practice was carried out in accordance with the TDY 1998 principles, the concept of structural performance came into force with DBYBHY 2007. Therefore, performance goal is not observed while strengthening.

The purpose of this study is to design and construct a reinforced concrete residential building, which has been constructed and constructed in advance of DBYBHY 2007 and is considered to be moderately damaged after the 1999 Marmara Earthquake. method (mode combination method) to determine the performance.

For this aim, a 4-storey residential building with reinforced concrete frame system, which was designed and built in 1987, was constructed and reinforced after the 1999 Marmara Earthquake (in 2000). The results are presented in graphical and tabular form.
\end{abstract}

Keywords: Strengthened, performance, Structural Behaviour, Relative storey displacement, linear elastic analysis

\section{Özet}

17 Ağustos 1999 tarihli Marmara depreminin ardından "Orta Hasarlı" olarak belirlenen birçok yapı güçlendirilerek kullanılmaya devam etmektedir. Güçlendirme uygulaması TDY 1998 esaslarına göre yapılırken yapısal performans kavramı DBYBHY 2007 ile yürürlüğe girmiştir. Bu nedenle güçlendirme yapilırken performans hedefi gözetilmemiştir.

Bu çalışmanın amacı, DBYBHY 2007'den önce projelendirilip, inşa edilmiş ve 1999 Marmara Depremi sonrasında orta hasarlı olarak değerlendirildiği için güçlendirme uygulaması yapılmış mevcut bir betonarme konut yapısının, ilk halinin (güçlendirilmemiş hal) ve güçlendirilmiş halinin DBYBHY 2007'de yer alan doğrusal elastik hesap yöntemine (mod birleştirme yöntemi) göre performansının belirlenmesidir.

Bu amaçla 1987 yılında projelendirilip inşası tamamlanan, 1999 Marmara Depremi sonrası (2000 yılında) güçlendirme projeleri hazırlanıp güçlendirilen betonarme çerçeve sisteme sahip 4 katlı bir konut yapısı incelenmiştir. Elde edilen sonuçlar, grafik ve tablo halinde sunulmuştur.

Anahtar Kelimeler: Güçlendirme, performans, yapısal davranış, göreli kat ötelemesi, doğrusal elastik analiz

*Corresponding author: Address: Faculty of Engineering, Department of Civil Engineering Sakarya University, 54187, Sakarya TURKEY. E-mail address: mert@sakarya.edu.tr, Phone: +902642955743 


\section{Giriş}

17 Ağustos 1999 tarihli depremde yaşanan büyük can ve mal kayıları bunların bir sonucu olmuş ve gerek yönetmeliklerde gerek ise uygulamada değişikliklere gidilmesini zorunlu olmuştur. $\mathrm{Bu}$ nedenle 2007 yılında yürürlüğe giren DBYBHY ile performans kavramı getirilmiştir.

Deprem performansı, tanımlanan deprem etkisi altında bir binada oluşabilecek hasar düzeyine ve dağılımına bağlı olarak belirlenen yapı güvenliği durumu olarak tanımlanabilir (Şahin, 2014).

2007 yılında yürürlüğe giren DBYBHY Bölüm 7 (Mevcut Binaların Değerlendirilmesi ve Güçlendirilmesi) deprem bölgelerinde bulunan mevcut ve güçlendirilecek bina ve bina türü yapıların deprem etkileri altındaki performanslarının değerlendirilmesinde uygulanacak hesap kurallarını, güçlendirme kararlarında esas alınacak ilkeleri ve güçlendirilmesine karar verilen binaların güçlendirme tasarımı ilkelerini içermektedir.

Bu konu ile ilgili birçok çalışma gerçekleştirilmiştir. Uygun ve Celep (2007) tarafından hazırlanan çalışmada performans analizinde kullanılan hesap yöntemlerinden bahsedilmiş ve bu hesap yöntemleri karşılaştırılmıştır. Çalışmada süneklik düzeyi yüksek kiriş ve kolonlardan oluşan beş katlı, çerçeve sistemli bir yapı incelenmiştir. Çalışma sonucunda 'doğrusal olan yöntemin daha tutucu sonuçlar verdiği, uygulama bakımından çözümlemesinin daha basit olduğu, doğrusal olmayan yöntemin daha elverişli ve doğrusal yönteme paralel sonuçlar verdiği, buna karşılık doğrusal olmayan dinamik yöntem sonuçlarının diğer iki yöntemin sonuçlarından uzak olduğu ' gözlemlerine varılmıştır. Demir ve ark., (2013) tarafından hazırlanan çalışmada mevcut betonarme binaların doğrusal elastik ve doğrusal elastik olmayan hesap yöntemleri ile incelenmesi üzerine bir değerlendirmede bulunulmuştur. Hesap yöntemlerinin kıyaslanması çalışmasında toplam yüksekliği 25m'den az, toplam kat adedi 8'i aşmayan, burulma düzensizlik katsayısı $\eta$ bi $<1,4$ olan 10 adet farklı illerdeki yapı incelenmiş, Sap2000 programı yardımı ile performans analizleri yapılmıştır. Uçar ve Merter (2012) tarafından hazırlanan çalışmada doğrusal elastik hesap yönteminden bahsedilmiştir. Yapılan çalışmada 5, 8 ve 10 katlı, yüksek süneklik düzeyine sahip yapılar Sap2000 programı yardımı ile incelenmiştir. Gökalp ve Bağcı (2009) tarafından hazırlanan çalışmada mod birleştirme yöntemi ile yapı güvenliğinin belirlenmesi konusu incelenmiştir. Çalışmada performans kavramı ve mod birleştirme yöntemi ile ilgili teorik bilgilere yer verilmiş örnekler ile konunun detaylı irdelemesi yapılmıştır. Yılmaz (2008) tarafından hazırlanan çalışmada mevcut bir betonarme yapının performans değerlendirmesi yapılmıştır. Çalışmada altı katlı mevcut bir konut binasının artımsal eşdeğer deprem yükü yöntemi, itme analizi ile performans analizi yapılmıştır. Karakaya (2013) tarafından hazırlanan çalışmada ikiden sekiz kata kadar aynı kat planına sahip yedi farklı yapı tasarlanmış, bu modeller mevcut yapı kabul edilmiş ve doğrusal olmayan yöntemlerle performans değerlendirmesi yapılmıştır. Yapılan analiz çalışması sonucunda elde edilen sonuçlar sunulmuş ve yorumlanmıştır.

Bir yapının performansı demek, daha önce belirlenen deprem riskleri altında yapının ne düzeyde hasar göreceği ve bu hasarın yapının güvenliğini ve kullanımını hangi düzeyde etkileyeceğini daha gerçekçi olasılıklarla tahmin etmektir. (Sucuoğlu, 2015). 2007 yılında yürürlüğe giren DBYBHY de yap1 sistemlerinin deprem performanslarının belirlenmesinde, doğrusal ve doğrusal olmayan değerlendirme yöntemleri kullanılmaktadır. Doğrusal elastik yöntem çözümü her ne kadar doğrusal olsa da değerlendirme yönteminde sistemin elastik ötesi davranışı dikkate alınmaktadır 
Doğrusal elastik yöntemin matematiksel anlamda "doğrusal" olduğunu kabul etmek uygun değildir. Yeni tasarımı yapılacak binalarda, doğrusal olmayan davranışla oluşacak yatay yük kapasite artımı tüm bina için öngörülen taşıyıcı sistem davranış katsayısı $R$ ve ona bağlı kullanılan deprem yükü azaltma katsayısı $\mathrm{Ra}(\mathrm{T})$ ile göz önüne alınmaktadır (Sezer ve ark., 2007). Depremden kaynaklanan tüm iç kuvvetlerin aynı yük azaltma faktörü ile azaltılmasının gerekçesi, binanın deprem sırasında tek dereceli bir sistem gibi davranacağı varsayımıdır (Sucuoğlu, 2006).

Mevcut binaların değerlendirilmesinde kullanılan doğrusal elastik değerlendirme yönteminde her eleman için göz önüne alınan etki/kapasite oranı $r$ katsayısı ile doğrusal olmayan davranışla oluşacak yatay yük kapasite artımı göz önüne alınmaktadır. Diğer bir ifade ile çözüm işlemi doğrusal olmakla beraber bu yöntemde de taşıyıcı sistemin doğrusal olmayan davranışı göz önüne alınmaktadır (Sezer ve ark., 2007).

\subsection{Bina Performansının Doğrusal Elastik Hesap Yöntemleri ile Belirlenmesi}

2007 DBYBHY 2 ve 7. bölümlerinde belirtildiği üzere bina performansının doğrusal elastik hesap yöntemleri ile belirlenebilmesi için iki farklı hesap yöntemi bulunmaktadır. Bu hesap yöntemlerinden ilki Eşdeğer Deprem Yükü Yöntemi, ikincisi ise Mod Birleştirme Yöntemidir. Yapılmış olan çalışmada Mod Birleştirme Yöntemi kullanılmıştır. Bu yöntemde maksimum iç kuvvetler ve yerdeğiştirmeler, binada yeterli sayıda doğal titreşim modunun her biri için hesaplanan maksimum katkıların istatistiksel olarak birleştirilmesi ile elde edilir.

Bu yöntemde, herhangi bir n'inci titreşim modunda gözönüne alınacak azaltılmış ivme spektrumu ordinatı Denk.(1.1) ile belirlenmektedir

$$
S_{a R}\left(T_{n}\right)=\frac{S_{a e}\left(T_{n}\right)}{R_{a}\left(T_{n}\right)}
$$

Burada $S_{a R}\left(T_{n}\right)$ n'inci doğal titreşim modu için azaltılmış spektral ivmeyi [m/s2], $S_{a e}\left(T_{n}\right)$ n'inci doğal titreşim modu için elastik spektral ivmeyi [m/s2], $R_{a}\left(T_{n}\right)$ n'inci doğal titreşim modu için deprem yükü azaltma katsayısını ifade etmektedir.

Deprem yüklerinin belirlenmesi için esas alınacak olan spektral ivme katsayısı, A(T), etkin yer ivmesi katsayısı $A_{o}$ '1n bina önem katsayısı, $I$ ve spektrum katsayısı $S(T)$ ile çarpılmasıyla elde edilmektedir [Denk.(1.2)]. \%5 sönüm oranı için tanımlanan elastik ivme spektrumunun ordinatı olan elastik spektral ivme, $\mathrm{S}_{\mathrm{ae}}(\mathrm{T})$, spektral ivme katsayısı ile yerçekimi ivmesi g'nin çarpımına karşı gelmektedir [Denk.(1.3)].

$$
\begin{gathered}
A(T)=A_{o} I S(T) \\
S_{a e}(T)=A(T) \mathrm{g}
\end{gathered}
$$

Yapılmış olan çalışmada süneklik düzeyleri iki doğrultu içinde aynı kabul edilmiştir. Yüksek sünekliliğin bulunduğu durumlar için $\mathrm{R}(\mathrm{x})=6, \mathrm{R}(\mathrm{y})=6$ olarak kabul edilmiş, normal sürekliliğin bulunduğu durumlar için $\mathrm{R}(\mathrm{x})=4, \mathrm{R}(\mathrm{y})=4$ olarak kabul edilmiştir Zemin sınıfı Z3 , deprem bölgesi 1. Derece, Bina kullanım amacı konut ve bina önem katsayısı 1 alınmıştır. 


\section{Problemin Tanımı ve Analizleri}

İncelenen konut binası kat yükseklikleri değişkenlik göstermekte olup Zemin Kat yüksekliği 3,60 metre, 1,2 ve 3. Normal Kat yükseklikleri 2,90 metredir. Yapı X ve Y yönlerinde simetrik olmamakla birlikte $93 \mathrm{~m}^{2}$ 'lik bir alan üzerine oturmaktadır(Şekil 1).

Mevcut yapıda döşeme kalınlıkları $12 \mathrm{~cm}$, kiriş boyutları 20x60 cm, kolon boyutları 25x30 cm, $25 \times 40 \mathrm{~cm}, 25 \times 50 \mathrm{~cm}$ olarak değişkenlik göstermektedir. Model1 olarak tanımlanan Mevcut yapıya ait bina özellikler Tablo 1 de verildiği gibidir.

Tablo 1.1 Model 1 Bina genel özellikleri

\begin{tabular}{|c|c|c|c|c|}
\hline \multicolumn{5}{|c|}{ Bina Genel Bilgileri } \\
\hline Açıklama & \multicolumn{4}{|c|}{ Bilgiler } \\
\hline Kat Adedi & \multicolumn{4}{|c|}{ Zemin +3 Normal Kat } \\
\hline Kullanım Amacı & \multicolumn{4}{|c|}{ Konut } \\
\hline Yap1 Süneklilik Düzeyi & \multicolumn{4}{|c|}{ Normal } \\
\hline Bina Önem Katsayısı (I) & \multicolumn{4}{|c|}{1} \\
\hline Bina Taşıyıcı Sistemi & \multicolumn{4}{|c|}{ Betonarme Çerçeveli Sistem } \\
\hline Zemin Sınıfi & \multicolumn{4}{|c|}{$\mathrm{Z3}$} \\
\hline Spektrum Karakteristik Periyotları & \multicolumn{4}{|c|}{$\mathrm{Ta}=0,15 \mathrm{sn} \quad \mathrm{Tb}=0,60 \mathrm{sn}$} \\
\hline Zemin Emniyet Gerilmesi & \multicolumn{4}{|c|}{$\sigma_{\mathrm{em}}=200 \mathrm{kN} / \mathrm{m}^{2}$} \\
\hline Deprem Bölgesi & \multicolumn{4}{|c|}{ 1'inci Derece Deprem Bölgesi } \\
\hline Etkin Yer İvmesi Katsayısı $A_{o}$ & \multicolumn{4}{|c|}{0,4} \\
\hline Temel Tipi & \multicolumn{4}{|c|}{ Tekil Temel } \\
\hline Malzeme & \multicolumn{4}{|c|}{ Beton Sınıfı : C14, Çelik Sınıfı : S220 } \\
\hline \multirow{2}{*}{ Beton Sinıfi : C14 } & Fck (Mpa) & Fctk (Mpa) & Fcd (Mpa) & Fctd (Mpa) \\
\hline & 14 & 1,3 & 9,3 & 0,87 \\
\hline \multirow{2}{*}{ Çelik Sınıfı : S220 } & Fyk (Mpa) & Fyd (Mpa) & & \\
\hline & 220 & 191 & & \\
\hline \multirow{2}{*}{ Kat Yükseklikleri (m) } & Zemin & 1 & 2 & 3 \\
\hline & 3,6 & 2,9 & 2,9 & 2,9 \\
\hline
\end{tabular}

Mevcut binanın kullanım amacı ve türüne göre deprem aşılma olasılığı, 50 yılda \%10 olarak seçilmiş ve hedeflenen performans düzeyi DBYBHY 2007'ye göre can güvenliği (CG) olarak belirlenmiştir.

Mevcut bina(Model 1) binanın ilk inşa edildiği güçlendirilmiş durumu ifade etmektedir. 

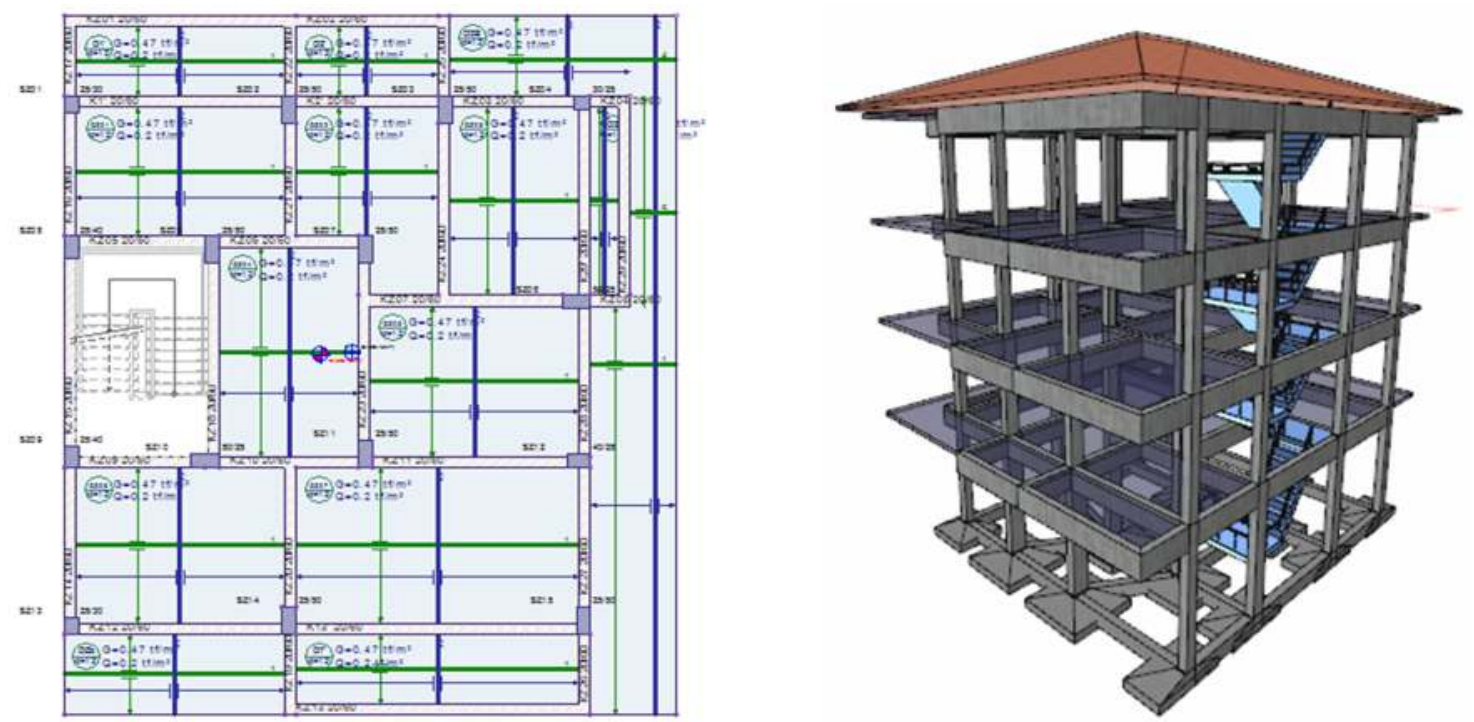

Şekil 1. Model 1(Mevcut ) binasının zemin kat kalıp planı ve 3 boyutlu hesap modeli

Model 2 mevcut yapıya yapılan güçlendirilmiş yapı modelini tanımlamaktadır. Bu çalışmalar kapsamında, mevcutta bulunan 7 adet kolon güçlendirilmiştir. Bu kolonlardan 3 tanesi 70/45 cm boyutlarına (SZ04, SZ11, SZ15), 4 tanesi 80/40 cm boyutlarına (SZ01, SZ05, SZ09, SZ13) getirilmiştir. Ayrıca mevcut sisteme ilave olarak 20 ve $25 \mathrm{~cm}$ genişliklerinde 20 adet perde ilave edilmiştir. Zemin kattan başlanılarak ilave edilen perdelerden, $20 \mathrm{~cm}$ genişliğinde olanlar (2 adet) sadece zemin katta bulunmakta olup $25 \mathrm{~cm}$ geniş̧liğinde olanlar (6 adet) Zemin kattan başlayıp 2 . Kat tavanında son bulmuştur. Mevcut temel tipi tekil temel olmasından dolayı perde bölümlerine sürekli temeller ilave edilmiştir. Mevcut güçlendirilmiş yapının 3.normal katında herhangi bir güçlendirme uygulaması yapılmamıştır(Şekil 2)
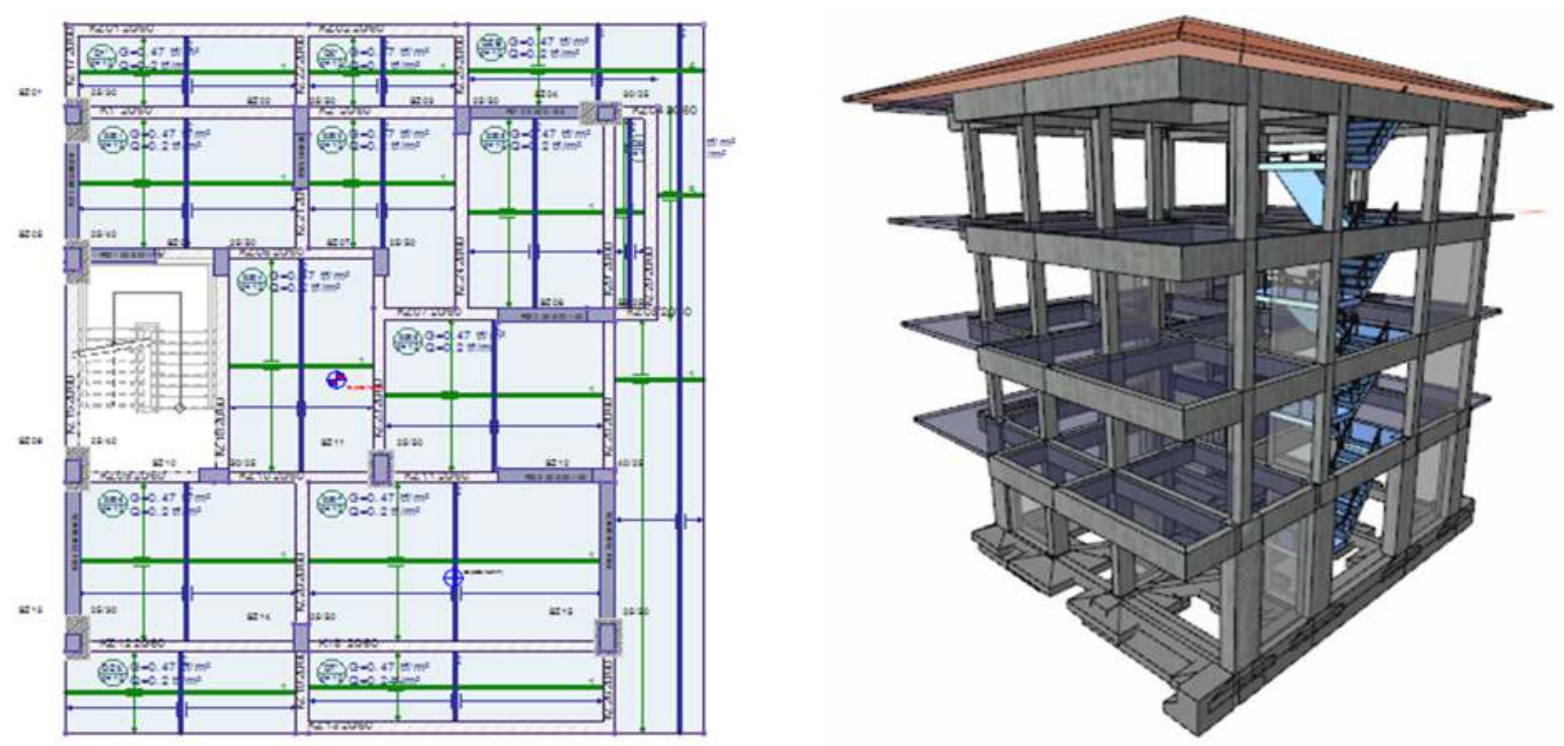

Şekil 2. Model 2(Güçlendirilmiş ) binasının zemin kat kalıp planı ve 3 boyutlu hesap modeli 
Model 3 ise DBYBHY 2007 esaslarına göre gerekli performans hedefini sağlayacak şekilde güçlendirilmiş yapı modelini tanımlamaktadır. Yapılmış olan güçlendirme çalışmasında mevcutta bulunan 14 adet kolon güçlendirilmiştir(Şekil 3). $\mathrm{Bu}$ güçlendirme çalışmalarında 'SZ01,S101,S201,S301' kolonlar1 3 kenarından 15'er cm olacak şekilde mantolanmış, 'SZ05' kolonu 3 kenarından 10'ar cm olacak şekilde mantolanmış, 'SZ11,S111,S211,S311' kolonlar1 4 kenarından 10'ar cm olacak şekilde mantolanmış, 'SZ14' kolonu 4 kenarından 10'ar cm olacak şekilde mantolanmış, 'SZ15,S115,S215,S315' kolonları ise 4 kenarından 15'er cm olacak şekilde mantolanmıştır. Ayrıca mevcut sisteme ilave olarak $25 \mathrm{~cm}$ genişliğinde 16 adet güçlendirme perdesi (PZ01, PZ02, PZ03, PZ04, P101, P102, P103, P104, P201, P202, P203, P204, P301, P302, P303, P304) ilave edilmiştir. Mevcut temel tipi tekil temel olmasından dolayı perde bölümlerine sürekli temeller ilave edilmiştir.
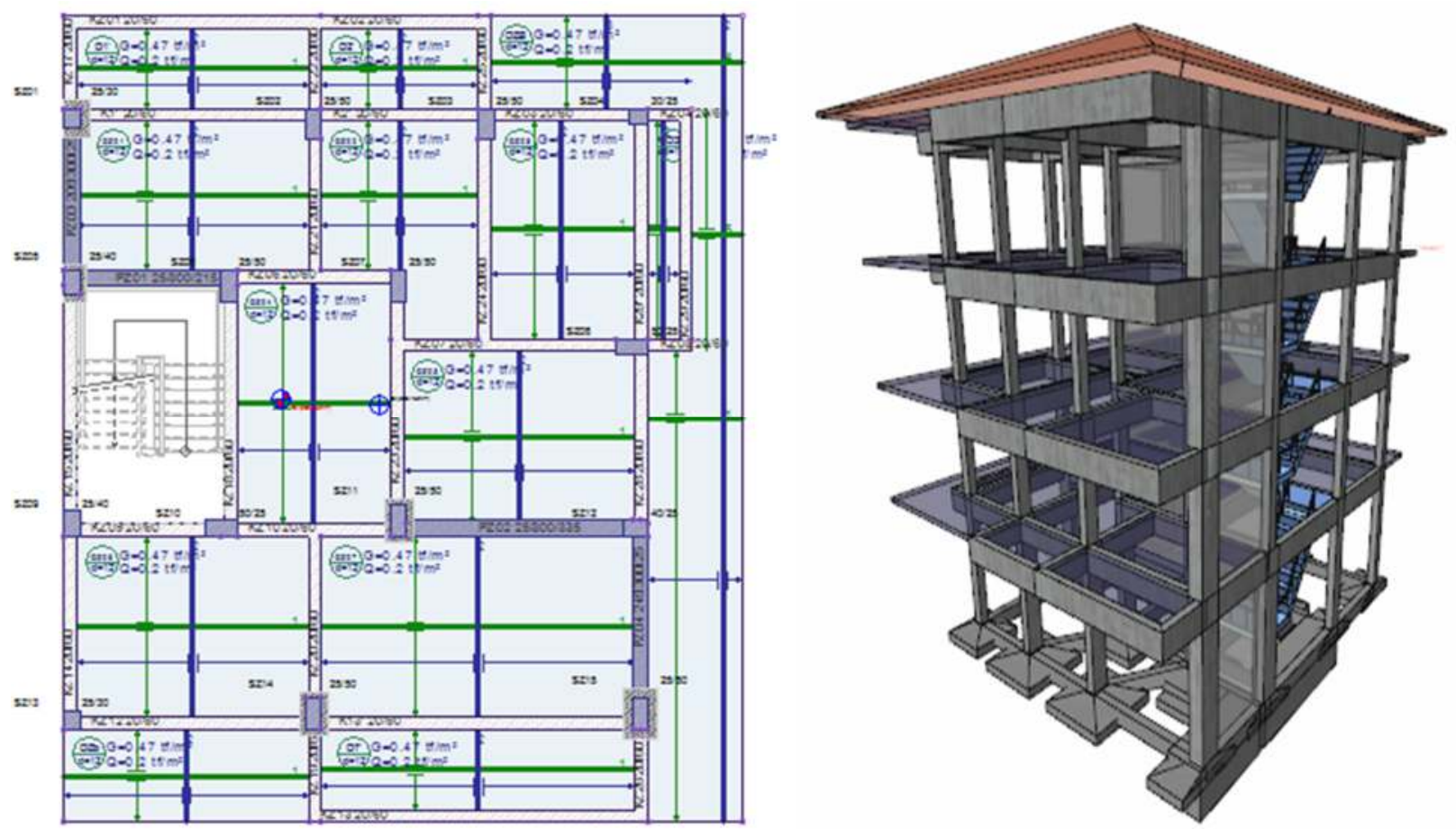

Şekil 3. Model 3 TDY 2007 esaslarına göre güçlendirilmiş binanın zemin kat kalıp planı ve 3 boyutlu hesap modeli

Güçlendirmede mantolama ve ilave perde için C30 S 420 malzemesi seçilmiştir. İlave perdeler ve manto uygulaması bütün katlarda gerçekleştirilmiştir.

Hazırlanan bu üç model için gerçekleştirilen analiz sonucunda periyot, göreli kat ötelemesi, kat deplasmanları, burulma düzensizliği ve performans durumu ayrıntılı olarak incelenmiştir. 


\subsection{Mod Birleştirme Yöntemi ve Performans Analizi Esasları}

Mod birleştirme yöntemi tüm binalar için uygulanabilecek bir yöntemdir. Bu yöntemde maksimum iç kuvvetler ve yerdeğiştirmeler, binada yeterli sayıda doğal titreşim modunun her biri için hesaplanan maksimum katkıların istatistiksel olarak birleştirilmesi ile elde edilir. Mod birleştirme yöntemi ile hesapta Denk.(1.1)'de $\mathrm{R}_{\mathrm{a}}=1$ alınacaktır. Uygulanan deprem doğrultusu ve yönü ile uyumlu eleman iç kuvvetlerinin ve kapasitelerinin hesabında, bu doğrultuda hakim olan modda elde edilen iç kuvvet doğrultuları esas alınacaktır. Döşemelerin yatay düzlemde rijit diyafram olarak çalıştığı binalarda, her bir katta, birbirine dik doğrultularda iki yatay serbestlik derecesi ile kütle merkezinden geçen düşey eksen etrafındaki dönme serbestlik derecesi gözönüne alınacaktır. Her katta modal deprem yükleri bu serbestlik dereceleri için hesaplanacak, ancak ek dış merkezlik etkisi'nin hesaba katılabilmesi amacı ile, deprem dorultusuna dik doğrultudaki kat boyutunun +\%5'i ve -\%5'i kadar kaydırılması ile belirlenen noktalara ve ek bir yükleme olarak kat kütle merkezine uygulanacaktır

Hesaba katılması gereken yeterli titreşim modu sayısı, Y, gözönüne alınan birbirine dik x ve y yatay deprem doğrultularının her birinde, her bir mod için hesaplanan etkin kütlelerin toplamının hiçbir zaman bina toplam kütlesinin \%90'ından daha az olmaması kuralına göre belirlenecektir.

$$
\begin{gathered}
\sum_{n=1}^{Y} M_{x n}=\sum_{n=1}^{Y} \frac{L_{x n}^{2}}{M_{n}} \geq 0.90 \sum_{i=1}^{N} m_{i} \\
\sum_{n=1}^{Y} M_{y n}=\sum_{n=1}^{Y} \frac{L_{y n}^{2}}{M_{n}} \geq 0.90 \sum_{i=1}^{N} m_{i}
\end{gathered}
$$

Denk.(1.4)'de yer alan $L_{x n}$ ve $L_{y n}$ ile modal kütle $M_{n}$ 'nin ifadeleri, kat döşemelerinin rijit diyafram olarak çalıştı̆̆ binalar için aşağıda verilmiştir

$L_{x n}=\sum_{i=1}^{N} m_{i} \Phi_{x i n} \quad ; \quad L_{y n}=\sum_{i=1}^{N} m_{i} \Phi_{y i n}$
$M_{n}=\sum_{i=1}^{N}\left(m_{i} \Phi_{x i n}^{2}+m_{i} \Phi_{y i n}^{2}+m_{\theta i} \Phi_{\theta i n}^{2}\right.$

Mn, n'inci doğal titreşim moduna ait modal kütle değerini ifade etmektedir.

Binaların deprem performansı, uygulanan deprem etkisi altında binada oluşması beklenen hasarların durumu ile ilişkilidir ve dört farklı hasar durumu esas alınarak tanımlanmıştır. Performans değerlendirmesinde, kritik kesitlerinin hasarı MN'ye ulaşmayan elemanlar minimum hasar bölgesinde, MN ile GV arasında kalan elemanlar belirgin hasar bölgesinde, GV ve GÇ arasında kalan elemanlar ileri hasar bölgesinde, GÇ'yi aşan elemanlar ise göçme bölgesinde yer alırlar.

Hedeflenen performas düzeyi 50 yılda oluşma olasılı̆gı $\% 10$ olan şiddetli depremlerde Can Güvenliğ(CG) değerinin sağlanmasıdır 


\section{Sonuçlar ve Değerlendirmeler}

Çalışma kapsamında yapılan performans analizlerinde DBYBHY'te yer alan doğrusal elastik hesap yöntemlerinden mod birleştirme yöntemi kullanılmış, binanın kullanım amacı ve türüne göre deprem aşılma olasılığı, 50 yılda \%10 olarak seçilmiş ve hedeflenen performans düzeyi can güvenliği (CG) olarak belirlenmiştir.

Mevcut binanın ilk halinin ve güçlendirilmiş halinin DBYBHY'te yer alan konutlar için istenen can güvenliği performans seviyesini karşılamadığı görülmüştür. Bunun sonucu olarak çalışmaya DBYBHY kriterlerine uygun yeni bir güçlendirme önerisi sunulması ile devam edilmiştir.

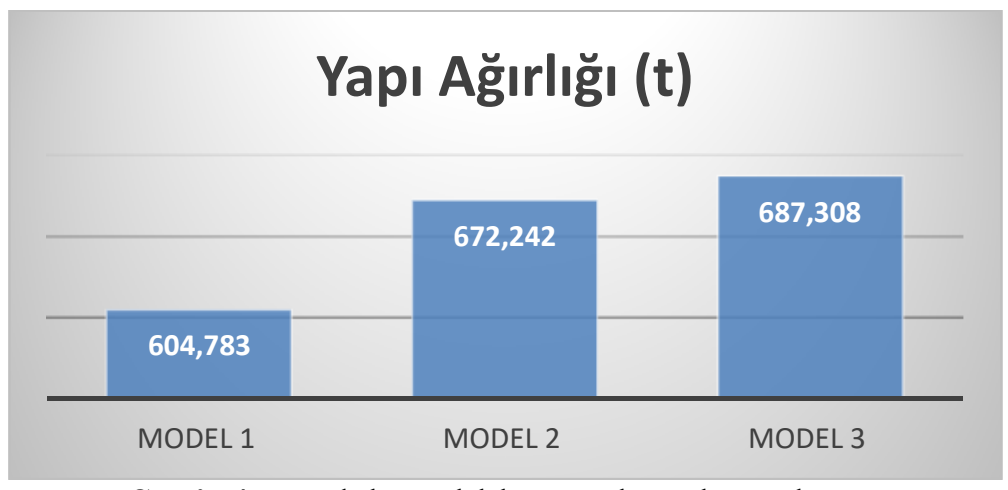

Şekil 4. Model ağırlıklarının karşılaştırılması

Şekil 4'te modellere ait yapı ağırlıkları sunulmuştur. 687,308 ton ile Model 3 en yüksek yapı ağırlığına sahip olurken, 604,783 ton ile Model 1 en düşük yapı ağırlığına sahip olmuştur. Bu durumun başlıca nedenleri, Model 3'te kullanılan güçlendirme perde genişliklerinin Model 2'ye göre daha büyük olması ve Model 3'te kullanılan güçlendirme kolon manto sayısının Model 2'den daha fazla olmasıdır.
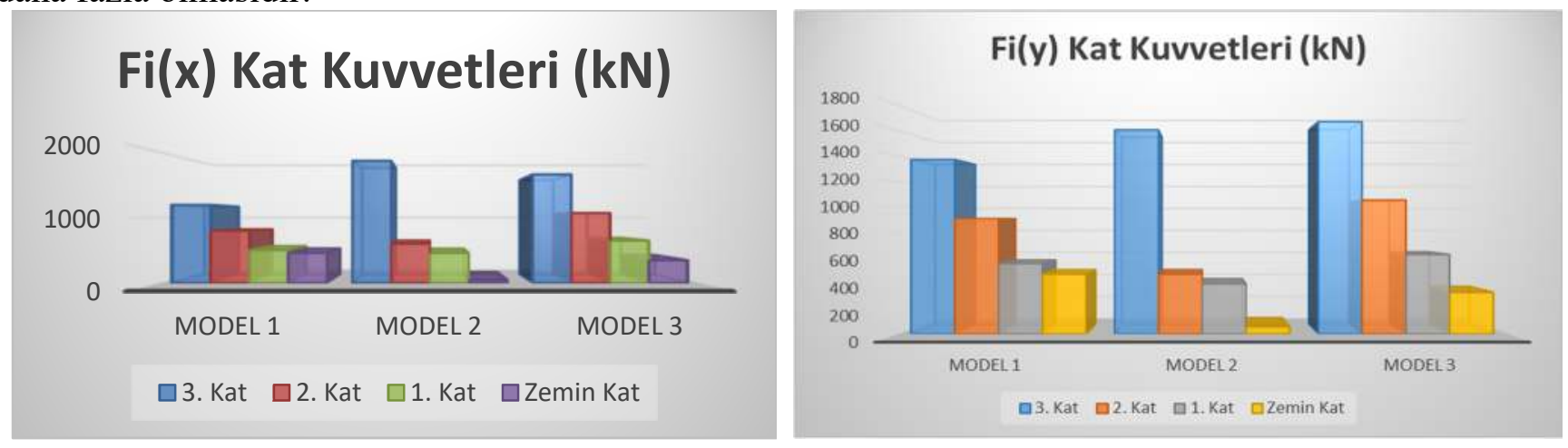

Şekil 5. X ve Y yönü kat kuvvetlerinin karşılaştırılması 


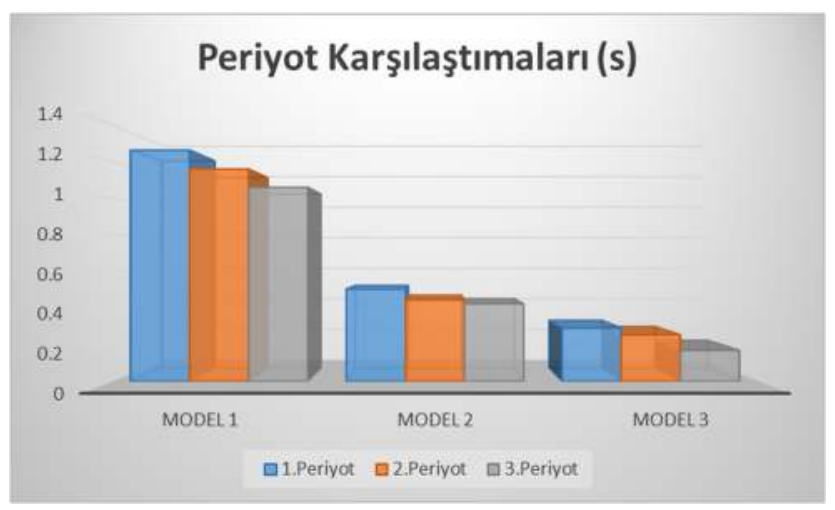

Şekil 6 . Modeller arası ilk üç hakim periyodun karşılaştırılması

Şekil 6'da modellere ait ilk üç periyot sunulmuştur. Şekilde belirtildiği üzere en yüksek değere sahip hakim periyot Model 1'de, en düşük değere sahip hakim periyot ise Model 3'te oluşmuştur. Model 2 ve 3 'te güçlendirme ile birlikte eklenen perde ve mantolanan kolonlar neticesinde yap1 ağırlığı ve rijitliği artmış, bunun sonucu olarak periyot düşmüş̧ür.
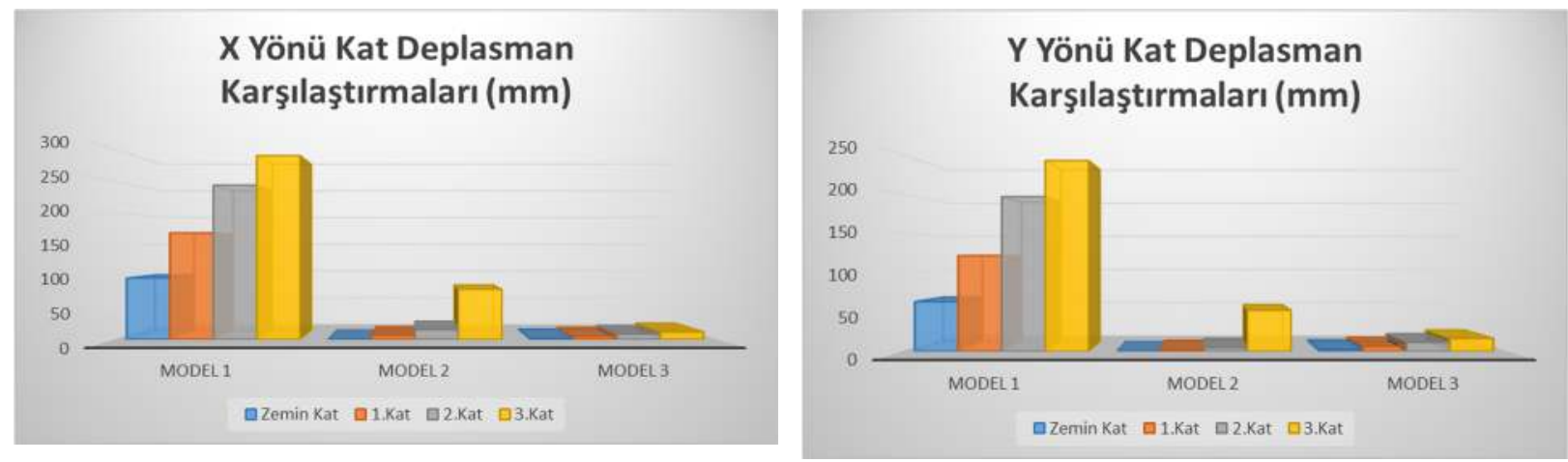

Şekil 7. X ve Y yönü kat deplasmanlarının karşılaştırılması

Şekil 7'de modeller içerisindeki katlarda yer alan, en yüksek X ve Y yönü kat deplasman değerine sahip yapı elemanlarının, kat deplasman değerleri sunulmuştur. Model 1 her bir kat için en yüksek deplasman değerlerine sahip modeldir. Model 2 ve 3'te yapılan güçlendirme çalışmaları yapının ilk halinde oluşan deplasmanları azaltmış, Şekil 7.'de belirtildiği seviyelere indirgemiştir. Ayrıca Model 2'nin 2.Normal katında yer alan maksimum kat deplasman değerinin 15,58 mm olmasına rağmen 3.Normal katında maksimum kat deplasman değerinin 78,96 mm olduğu görülmüştür. $\mathrm{Bu}$ durumun başlıca nedeni, yapı üzerine uygulanan güçlendirme çalışmalarının 3. Normal kata kadar devam ettirilmemesi (kolon mantoları, güçlendirme perdeleri) ve 3.Normal katta herhangi bir güçlendirme uygulamasının yapılmamasıdır

Tablo 2'de X ve Y yönleri için ayrı olacak şekilde, her bir kattaki maksimum göreli kat öteleme değerine sahip eleman değeri ile birlikte belirtilmiştir. Elde edilen değerler her bir eleman için ayrı ayrı Tablo 6.8'deki sınır değerler ile karşılaştırılmış ve elemanların hasar bölgeleri belirlenmiş̧ir. 
Tablo 2 Model 3 Göreli kat ötelemeleri

\begin{tabular}{|c|c|c|c|c|c|c|c|c|c|c|}
\hline $\begin{array}{c}\text { Kat Genel } \\
\text { Ayarları }\end{array}$ & \multicolumn{5}{|c|}{ X Yönü } & \multicolumn{5}{|c|}{ Y Yönü } \\
\hline Kat & Eleman & $\begin{array}{c}\boldsymbol{\delta}_{\boldsymbol{j i}} \\
(\mathrm{mm})\end{array}$ & $\begin{array}{l}\boldsymbol{h}_{j i} \\
(\mathrm{~m})\end{array}$ & $\frac{\delta_{j i}}{h_{j i}}$ & $\begin{array}{c}\text { Hasar } \\
\text { Bölgesi }\end{array}$ & Eleman & $\begin{array}{c}\boldsymbol{\delta}_{\boldsymbol{j i}} \\
(\mathrm{mm})\end{array}$ & $\begin{array}{l}\boldsymbol{h}_{\boldsymbol{j i}} \\
(\mathrm{m})\end{array}$ & $\frac{\delta_{j i}}{h_{j i}}$ & $\begin{array}{c}\text { Hasar } \\
\text { Bölgesi }\end{array}$ \\
\hline 3. Kat & P3303 & 3,65 & 2,30 & 0,002 & Minimum & P3303 & 5,12 & 2,30 & 0,002 & Minimum \\
\hline 2. Kat & P2203 & 3,57 & 2,30 & 0,002 & Minimum & P2203 & 4,91 & 2,30 & 0,002 & Minimum \\
\hline 1. Kat & P1103 & 2,96 & 2,30 & 0,001 & Minimum & P1103 & 3,95 & 2,30 & 0,002 & Minimum \\
\hline Zemin Kat & PZZ03 & 1,95 & 3,60 & 0,001 & Minimum & PZZ03 & 2,42 & 3,00 & 0,001 & Minimum \\
\hline
\end{tabular}

Yapılan analizler sonucunda binanın her iki yönde de hemen kullanım performansını sergilediği görülmüş̧ür. $\mathrm{Bu}$ öneride binaya güçlendirme perdeleri ve kolon mantoları ilave edilerek güçlendirme çalışması yapılmış olup güçlendirme perdelerinin yerleri belirlenirken düzensizliğin oluşmamasına ve binaya etkiyen toplam kesme kuvvetinin büyük çoğunluğunun güçlendirme perdeleri ile taşınmasına dikkat edilmiş, mevcut mimari durumu çok fazla değiştirmeden bir çözüme ulaşıllmıştır.

\section{Kaynaklar}

1. 2007, Deprem Bölgelerinde Yapılacak Binalar Hakkında Yönetmelik, Bayındırlık ve İskan Bakanlığı, Ankara.

2. 1975, Afet Bölgelerinde Yapılacak Yapılar Hakkında Yönetmelik, İnşaat Mühendisleri Odası, Ankara.

3. 2000, Betonarme Yapıların Tasarım ve Yapım Kuralları, Türk Standartları Enstitüsü, Ankara.

4. Celep, Z., 2007. Mevcut betonarme binaların deprem güvenliğinin değerlendirilmesi, İnşaat Mühendisleri Odası İstanbul Şubesi, Meslekiçi Eğitim Kursu.

5. Yilmaz, C., 2008. Statik itme analizi ile mevcut bir betonarme yapının performans değerlendirmesi. İstanbul Teknik Üniversitesi, Fen Bilimleri Enstitüsü, İnşaat Mühendisliği, Yüksek Lisans Tezi.

6. Karakaya, M., 2013. Betonarme taşıyıcı sistemlerin doğrusal olmayan yöntemlerle performansının değerlendirilmesi. İstanbul Teknik Üniversitesi, Fen Bilimleri Enstitüsü, İnşaat Mühendisliği, Yüksek Lisans Tezi.

7. Dedeoğlu, F., 2014. Betonarme binanın doğrusal elastik olmayan hesap yöntemi ile performans analizi. İstanbul Teknik Üniversitesi, Fen Bilimleri Enstitüsü, İnşaat Mühendisliği, Yüksek Lisans Tezi.

8. Şahin, H., 2014. Mevcut bir betonarme yapının artımsal eşdeğer deprem yükü yöntemi ile performansının değerlendirilmesi. İstanbul Teknik Üniversitesi, Fen Bilimleri Enstitüsü, İnşaat Mühendisliği, Yüksek Lisans Tezi.

9. Kıran, F., 2010. Binaların performans analizi için kullanılan doğrusal ve doğrusal olmayan analiz yöntemlerinin incelenmesi. Çukurova Üniversitesi, Fen Bilimleri Enstitüsü, İnşaat Mühendisliği, Yüksek Lisans Tezi. 